\title{
Thermodynamic limitations to nuclear energy deployment as a greenhouse gas mitigation technology
}

\author{
Joshua M. Pearce \\ Clarion University of Pennsylvania \\ 106 Peirce Science Center \\ Clarion, PA 16214-1232, USA \\ E-mail: jpearce@clarion.edu
}

\begin{abstract}
To both replace fossil-fuel-energy use and meet the future energy demands, nuclear energy production would have to increase by $10.5 \%$ per year from 2010 to 2050. This large growth rate creates a cannibalistic effect, where nuclear energy must be used to supply the energy for future nuclear power plants. This study showed that the limit of ore grade to offset greenhouse gas emissions is significantly higher than the purely thermodynamic limit set by energy payback times found in the literature. In addition, any use of nuclear energy directly contributes heat to the Earth, which the Earth must radiate into space by raising its temperature to maintain thermodynamic equilibrium. This is a relatively small effect, but as energy consumption grows it must be considered for a world powered by nuclear energy. The results of this study demand modesty in claims of 'emission-free nuclear energy' as a panacea for global climate destabilisation.
\end{abstract}

Keywords: climate change; energy; greenhouse gas emissions; life-cycle analysis; LCA; nuclear energy.

Reference to this paper should be made as follows: Pearce, J.M. (2008) 'Thermodynamic limitations to nuclear energy deployment as a greenhouse gas mitigation technology', Int. J. Nuclear Governance, Economy and Ecology, Vol. 2, No. 1, pp.113-130.

Biographical notes: Joshua $\mathrm{M}$. Pearce received his $\mathrm{PhD}$ in Materials (Engineering option) with a minor in Science, Technology and Society from the Pennsylvania State University. He also has two BSc degrees from Penn State in Physics and Chemistry along with a minor in Mathematics. His primary research concentration is in electronic device physics and materials physics, although his research interests also include applied sustainability (both in the USA and in developing countries), service learning and environmental stewardship. He is currently an Assistant Professor of Physics at the Clarion University of Pennsylvania where he coordinates both the Nanotechnology and the Sustainability: Science and Policy Programmes. 


\section{Introduction}

Humanity's rampant combustion of fossil fuel for energy and the resultant carbon dioxide $\left(\mathrm{CO}_{2}\right)$ emissions, a powerful greenhouse gas $(\mathrm{GHG})$, has resulted in global climate destabilisation (IPCC, 1995; 2001; 2007a). The consensus among the Intergovernmental Panel on Climate Change (IPCC) and the 1993 World Energy Council's Global Energy Scenarios to 2050 , is that if we maintain our trajectory towards continued climate destabilisation, the planet will reach a tipping point - a point of no return (Hoffert et al., 2002). Global warming is already occurring, and if combustion of fossil fuels continues, temperatures are projected to rise by between $1.8^{\circ} \mathrm{C}$ and $4{ }^{\circ} \mathrm{C}$ in the next 100 years (IPCC, 2007a). The IPCC warns that unmitigated climate change in the long term is likely to exceed the capacity of natural, managed and human systems to adapt (IPCC, 2007b). Clearly, it is in the global public's best interest to have an aggressive strategy to prevent serious harm to the global environment and the long-term viability of the human experiment. Although energy conservation, from even small changes of policies or behaviours that save energy and reduce emissions, in aggregate can have a profound effect on energy use and the global climate (Pearce and Russill, 2005; Pearce and Miller, 2006; Pearce and Hanlon, 2007; Pearce et al., 2007), it is generally agreed that a large source of alternative energy is needed (Hoffert et al., 2002; Kutscher, 2007; Pearce, 2002).

Both in the peer-reviewed literature and in the popular press there is the perception that, because nuclear energy does not produce $\mathrm{CO}_{2}$ as a by-product during electricity generation as do fossil fuels, it is an 'emission-free' source of energy, and it often is shown as 'zero emissions' in tables comparing energy sources (Domenici, 2004; Nuclear Energy Institute, 2007; Voorspools and D'haeseleer, 2000; Voorspools et al., 2005). The US Department of Energy, when issuing millions of dollars in grants, hoped to contribute to "assuring a new generation of engineers and scientists necessary for pursuing nuclear power - a safe, reliable, affordable and emissions-free source of energy" (US Department of Energy, 2007). Many energy experts have also begun to reconsider the use of nuclear energy specifically to prevent GHG emissions (Johansson et al., 1996; Sailor et al., 2000; Cheney et al., 2001; Gagnona et al., 2002; Rohatgi et al., 2002). For example, the US National Energy Policy Development Group stated, "Nuclear power today accounts for $20 \%$ of our country's electricity. This power source, which causes no greenhouse gas emissions, can play an expanding part in our energy future" (Cheney et al., 2001, p.xi). In addition, many famous environmentalists have argued for aggressive expansion of nuclear power to stave off climate change, such as James Lovelock, the father of the Gaia theory, Stewart Brand, the founder of the Whole Earth Catalog, the late British Bishop Hugh Montefiore, founder and director of Friends of the Earth, and Greenpeace founder Patrick Moore (Moore, 2006). Moore recently argued that "Nuclear energy is the only large-scale, cost-effective energy source that can reduce these [greenhouse gas] emissions while continuing to satisfy a growing demand for power" (2006). Unfortunately, however, these views are naïve, when viewed over the nuclear-fuel life cycle; every kilowatt hour of nuclear energy is responsible for some $\mathrm{CO}_{2}$ emissions. Are these emissions too much for nuclear energy to provide for the future global energy demands without the likely disastrous effects of maintaining a fossil-fueled civilisation? What are the effects of such emissions on mitigation possibilities in the context of rapid energy consumption growth? Will purely thermal effects be significant for the large amounts of global energy consumption predicted? 
This paper will answer these questions by focusing on the promise and limitations of nuclear energy as a climate change mitigation technology. It assumes that all the challenges $^{1}$ facing nuclear energy are solved in order to only consider the technical aspects of nuclear energy to mitigate climate change. First, the life-cycle emissions of nuclear energy will be reviewed and the required embodied energy for low-grade ore placed in perspective with the second law of thermodynamics. The rate of new power production needed will then be used to analyse the extent of a GHG emission reduction 'cannibalisation effect'. Next, the amount of thermal forcing from nuclear energy production to maintain the earth in thermodynamic equilibrium will be determined from current energy demand and possible future amounts of energy consumption. Finally, these effects will be combined to semiquantitatively determine the ability of nuclear energy to prevent global climate change.

\section{Life-cycle greenhouse gas emissions from nuclear energy}

In order to determine true sustainability, all energy technologies must undergo a comprehensive Life-Cycle Analysis (LCA). LCA is a means of quantifying how much energy and raw material are used and how much (solid, liquid and gaseous) waste is generated at each stage of a product's life (Pearce and Lau, 2002). Ideally an LCA would include measured quantification of material and energy needed for raw material extraction, manufacturing of all components, use requirements, generation (if any), end of use (disposal or recycling), and the distribution/transportation in between each stage. Complete LCAs are difficult to perform on any technology, including nuclear energy production, because there are always limits to the information available. For example, there is no reliable data for nuclear power plant-decommissioning energy requirements. Although GHG gases are not emitted during the harnessing of nuclear power itself, there are considerable emissions that result from the entire nuclear-fuel life cycle (as seen in Figure 1). The dashed arrows in Figure 1 denote an energy transfer, the solid arrows a materials transfer, and the solid arrows with circles trace the path of nuclear fuels (uranium) through the cycle. Each use of energy is responsible for additional emissions because of the current energy mix. The energy and emissions associated with transportation were omitted for clarity. As can be seen in Figure 1, the nuclear-fuel cycle consists of power plant construction, mining/milling uranium ores, fuel conversion, enrichment (or de-enrichment of nuclear weapons) and fabrication. Then the power plant uses some energy during operation, decommissioning, and for short- and long-term waste disposal.

There is serious disagreement between different studies in the literature as to the actual carbon dioxide equivalent $\mathrm{GHG}$ emissions per unit energy $\left(\mathrm{CO}_{2}\right.$ eq./ $\mathrm{kW}$-hr $)$ found for the nuclear-fuel cycle and extreme care must be taken when comparing studies with each other and with those of fossil fuels. Differences found in the studies are in part due to different energy efficiencies of enrichment techniques, different energy mixes of the geographical regions/countries being studied, and different methodologies. Some studies used process-based (PB) analyses, which do not fully capture the real impact of GHG emissions. For example, instrumentation and control-related energy is not included in any of the PB or materials-based analyses (Fthenakis and Kim, 2007). Not surprisingly, such 
studies found extremely low values for the nuclear-fuel cycle of $3.48 \mathrm{~g} \mathrm{CO}_{2}$ eq./kW-hr (Vattenfall, 2004). The most reliable method of calculating the emissions of any energy-producing technology is Economic Input/Output (EIO) analysis. EIO analysis can capture emissions associated with, for example, incremental energy required for the fabrication of complicated high-specification non-mass-manufactured components, which is ignored by the more restricted methods. EIO can capture embodied energy outside of the system being studied. Hondo (2005) used a mixture of EIO analysis and PB analysis to find $24.2 \mathrm{~g}-\mathrm{CO}_{2} / \mathrm{kW}-\mathrm{hr}$ for the nuclear cycle, which compares quite favourably to fossil-fuel sources: coal - 975.2, oil - 742.1, LNG-fired - 607.6 and LNGCC - 518.8. Following the model of Fthenakis and Kim (2007), the GHG emissions from the nuclear-fuel cycle were determined based on the most current literature for the USA, which thus did not include reprocessing that does not occur in the USA, but included additional stages that earlier work (DeLucchi, 1991) omitted such as spent-fuel disposal and the deconversion of depleted uranium.

Figure 1 Life-cycle flows for the US nuclear-fuel cycle as currently operated without fuel reprocessing

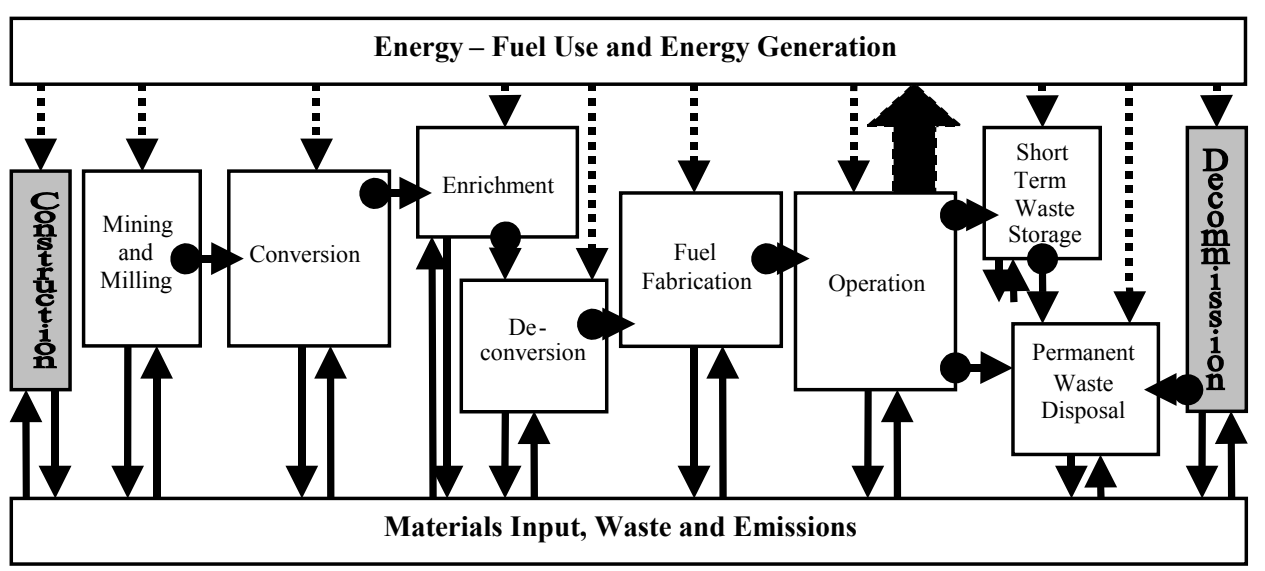

Notes: 1 dashed arrows $=$ simplified energy.

2 circle with arrows $=$ uranium.

3 solid arrows = other materials/emissions.

The energy and emissions associated with transportation between stages were omitted for clarity.

It should be noted clearly here that the emissions are highly dependent on the energy resources of the country or area under consideration. Here the US data is utilised because it is the most readily available. If the same analysis were performed in another less carbon-intensive electrical market or another country already heavily invested in nuclear energy (e.g., France), the life-cycle emissions would need to be taken into account for the nuclear energy being provided - but it would be less than if the same energy were provided by fossil fuels as is done now in the USA. The values would also change if nuclear energy were deployed on the large scale. It is non-trivial to determine the emissions for each additional kW-hr of nuclear energy as the energy mix changes. This raises an important area of future study, which will be discussed in Section 6 in greater detail. 


\subsection{Construction}

The estimates of GHG emissions from constructing nuclear power plants are primarily based on the 36000 metric tonnes of steel and 480000 metric tonnes concrete materials used, for a 1.1 GW plant (Oak Ridge National Laboratory, 1995).

\subsection{Mining and milling}

Uranium ore is mined both in surface (strip) mines and underground. The milling step involves crushing the uranium ore, grinding it into a fine slurry, and then leaching it with sulphuric acid. Uranium is then recovered from solution and concentrated to solid uranium oxide $\left(\mathrm{U}_{3} \mathrm{O}_{8}\right)$, known as 'yellow cake'. The baseline GHG factor for mining and milling in the US nuclear-fuel cycle is estimated to be $1.7 \mathrm{~g} \mathrm{CO}_{2}$-eq./kW-hr, calculated from the estimated energy consumption to explore for, mine and mill uranium, and the 1987-1990 average uranium-ore grade of $0.2 \% \mathrm{U}_{3} \mathrm{O}_{8}$ (DeLucchi, 1991). Energy usage for mining and milling ores increases considerably with low-grade ores (Chapman and Roberts, 1983) and sets one of the primary thermodynamic limits to nuclear energy production, discussed in Section 3.

\subsection{Conversion and enrichment}

Uranium oxide is converted into hexafluoride $\left(\mathrm{UF}_{6}\right)$; vapourised and fissionable ${ }^{235} \mathrm{U}$ is separated from ${ }^{238} \mathrm{U}$ and subsequently enriched either by gaseous diffusion or by gas centrifuge. Unfortunately, the USA relies solely on a gaseous diffusion for enrichment. The energy requirement for gaseous centrifuge enrichment ranges from 40 to $100 \mathrm{~kW}$-hr/SWU; whereas gaseous diffusion is much less efficient, requiring 2400 to 3000 kW-hr/SWU (DeLucchi, 1991; DeLucchi, 2003; Choppin et al., 2002).

In order to minimise the life-cycle GHG emissions in the short term, there is a better alternative - utilising uranium found in nuclear bombs. A considerable amount of highly enriched weapon-grade uranium $\left(>90 \%{ }^{235} \mathrm{U}\right)$, originally produced for warheads in Russia, is already diluted to fuel-grade uranium $\left(<5 \%{ }^{235} \mathrm{U}\right)$ and burned in US nuclear reactors in the 'Megatons to MegaWatts' Program (United States Enrichment Corporation, 2001). The Natural Resource Defense Council estimates that the USA possesses a current total stockpile of 10350 nuclear warheads with 5300 operational nuclear warheads (including 4530 strategic warheads and 780 non-strategic warheads) and almost 5000 additional warheads have been retained in the 'responsive reserve force' or are in an inactive status (Norris and Kristensen, 2005). By blending down this weapon-concentrated fissionable material, a considerable amount of energy can be generated without adding additional GHG from mining, concentrating, etc. This supply of fuel for nuclear energy should be utilised first because of its larger GHG emission mitigation potential than unmined uranium.

\subsection{Deconversion and fabrication}

Enriched $\mathrm{UF}_{6}$ is converted to fuel $\left(\mathrm{UO}_{2}\right)$ powder and shaped into small pellets that are stacked inside thin fuel rods made of a zirconium alloy or stainless steel, which are then sealed and assembled into fuel assemblies. The GHG emissions from conversion/fabrication are taken from the fuel- and material-use reported by the US Department of Energy (1983). 


\subsection{Operation}

In the reactor, the ${ }^{235} \mathrm{U}$ isotope fissions, producing heat, which is utilised to drive a turbine/generator to produce electricity. GHG emissions can be determined during nuclear power plant operation from the amount of fuel used for start-up of the auxiliary steam generators and in-plant heating, which uses between 0.1 to 3 million gal/year (Bowers et al., 1987; DeLucchi, 1991; Rotty et al., 1975). In addition, GHG emissions must be accounted for from annual expenses including maintenance and operation costs, including miscellaneous supplies, make-up materials and chemicals, and non-radioactive waste management.

\subsection{Short-term and long-term storage}

Spent nuclear fuels are highly radioactive and continue to generate heat even after reaching the end of their useful life. The USA does not reprocess nuclear fuels and reprocessing was not included in this study. Future work is needed to quantify the effect reprocessing would have on the analysis presented here. For 'short-term' storage, spent fuels are stored in water-filled pools or dry storage casks at the reactor site for further reprocessing or disposal in the future. Spent fuel rods for disposal are encapsulated in corrosion-resistant metals, such as copper or stainless steel, for future disposal or recycling (Argonne National Laboratory, 1999).

Nuclear waste from nuclear power plants will remain dangerous to humans and the environment for generations, so it is necessary to store it permanently. To estimate the emissions from permanent storage, it was assumed that all US waste would be kept at the Yucca Mountain Project (US Department of Energy, 2002a-b). The potential GHG emissions for constructing, transporting spent fuel, operating, monitoring, and closing a 'permanent' repository all must be estimated.

\subsection{Decommissioning}

Although all LCAs are difficult, the least reliable data set for the nuclear-fuel cycle comes from decommissioning, a stage for which no experimental data is available. Earlier studies (e.g., Chapman, 1975) completely ignore this stage, yet if it is to be done in an environmentally responsible way, the energy requirements and emissions are substantial (Storm van Leeuwen, 1985) because it would involve the following tasks:

- cleaning the reactor and other radioactive components by removal of contamination from surfaces of facilities or equipment by washing, heating, chemical or electrochemical action, or mechanical cleaning

- demolishing and cutting the nuclear reactor vessel, radioactive components and biological shield into small pieces (and the concomitant control for environmental contamination during the process)

- packing the radioactive debris and decontamination wastes for safe handling and for final disposal in a permanent repository

- transportation to that facility

- any maintenance of that facility. 
Clearly, it is unacceptable to exclude these energy investments from the nuclear life cycle when considering emissions mitigations, even though they come at the end of the life of the system.

\subsection{Transmission losses}

Nuclear power is not a distributed energy source and must act as a central power source because of both scale and the security necessary. Nuclear-generated electricity thus must be transmitted over long distances like the majority of electricity on the grid. Although high-voltage transmission lines do a lot to minimise electric resistance losses in wires, there is still an average transmission loss of $6 \%$ from the power plant over the grid to the end user (Energy Information Administration, 2005). Thus, because of the advent of commercial Distributed Generation (DG) technologies that do not suffer such losses, the nuclear electricity used to calculate the GHG emissions ratio to electricity must be penalised $6 \%$ in comparison.

Improvements in the grid could reduce this penalty; however, a much larger improvement could be made by evolving nuclear power plants into Combined Heat and Power (CHP) systems. CHP is the use of a power plant to simultaneously generate both electricity and useful heat. The status quo in US power plants is to emit excess heat created as a by-product of electricity generation into the environment as waste, usually through cooling towers (nuclear) or flue gas (coal, natural gas). CHP captures this 'waste' heat for domestic use (often seen in Europe) or industrial heating (or cooling via absorption chillers) purposes. Although nuclear power is still not considered safe enough by the public to be used for district heating (necessitating that the plant be physically located near or in the middle of a population centre), it is both possible and desirable (from a climate change mitigation perspective) to consider co-locating nuclear power plants and industrial factories with processes that require significant heat to make use of the currently wasted heat. CHP is thermodynamically the much more efficient use of the nuclear fission when compared to the status quo. Contrasted to the recent explosion in interest in cogeneration and CHP for natural gas plants and microgeneration (e.g., reciprocating engines, microturbines and fuel cells), relatively little work has been done on utilising nuclear energy as a CHP source. To begin this effort, new geographic information system techniques (Pearce et al., 2007) could be used to cluster eco-industrial parks and support facilities around nuclear power plants to utilise the thermal energy more efficiently.

\subsection{Total life-cycle emissions}

The total lifetime GHG emissions nuclear-fuel cycles in the USA were determined to be between 16-55 $\mathrm{g} \mathrm{CO}_{2}$-eq./kW-hr for nuclear energy by Fthenakis and Kim (2007). The lower value is primarily derived from the process-based studies discussed above, while the higher number utilised primarily EIO-based analysis. The average life-cycle GHG emission factor of the US electric mix (which includes coal, natural gas, hydroelectric, nuclear, and some non-hydro renewable energy sources such as wind and solar) is about $695 \mathrm{~g} \mathrm{CO}_{2}$-eq./kW-hr (Kim and Dale, 2005). Thus, in the best case scenario in the USA, nuclear energy provides a factor of 43 times less emissions than the status quo and in the more thorough case only about a factor of 12 times less emissions. 


\section{Uranium supply and the second law of thermodynamics}

As can be seen from the variability between the high-emission and low-emission cases summarised in Section 2.9, the emissions from the nuclear fuel cycle are highly variable depending on the input parameters. One of the most important factors that determine the GHG emissions for a given $\mathrm{kW}$-hr of nuclear electricity is the uranium concentration in the ore. The extraction energy is inversely proportional to the ore concentration. As the concentration decreases, the energy needed to extract and concentrate the uranium increases, as do the GHG emissions. The second law of thermodynamics thus demands at some point that the usability of nuclear-fuel resources as an energy supply is limited below the total terrestrial uranium limit, because the energy needed to extract and concentrate the uranium is equal to the usable energy provided by the fission reaction of the uranium. For the mining- and milling-embodied energy alone, this limit is 8 parts per million (ppm); if the embodied energy of the head of the life cycle is included, this limit is raised to $30-40 \mathrm{ppm}$ and in the worst-case scenarios in the USA, this limit is about $0.01 \%$ for the grade of ore (Storm van Leeuwen, 1985). Currently, producing $1 \mathrm{~kg}$ of enriched uranium generates approximately $7 \mathrm{~kg}$ of depleted uranium, containing less than $0.35 \%{ }^{235} \mathrm{U}$. This could be used as a source of fissionable ${ }^{235} \mathrm{U}$ in the future, but currently is stored in steel cylinders. This source and other sources of low-concentration uranium provide diminishing returns for GHG emission mitigation. With the grade of ore used today $(0.2 \%)$, this thermodynamic limit does not appear immediately important; however, if future energy needs (discussed in detail in the next section) are to be met with nuclear energy replacing fossil fuels to a large extent, thermodynamic limits become imperative in the very near future. This is because the most abundant supplies of terrestrial uranium (such as shales, granite, and either fresh water or sea water) have low grades and are thus eliminated as sources of useful fissionable material with current technology (Deffeyes and MacGregor, 1980). Based on current reserves, the world uranium supply may fall short of meeting future demands without going to the 'all nuclear energy' case. There is large debate over the available supplies of uranium and at what global capacity such lower-grade ores would be considered. For the purposes of this study it is optimistically assumed that such ores are available, although a recent International Atomic Energy Agency (2001) study concludes that, to meet the potential, gradual increase in uranium demands until 2050 (and modest by the scale of growth discussed above), more efforts are required to discover large, high-grade ores by 2010 so that new uranium production from them could begin by 2025 .

\section{Rate of energy demand increase and GHG emission reduction cannibalisation effect}

The climate challenge outlined in the Introduction is being significantly complicated by rapid increases in energy needs as the current and future poor elevate themselves out of poverty in developing countries, and those in developed countries find ever more creative means to accelerate the combustion of remaining fossil fuel supplies. The United Nations forecasts that the global population will reach 8.5 billion by 2050 and plateau at 10 billion by 2075 (Leeson, 2002). Eighty percent of this increased population is 
expected to reside in urbanised areas, which will lead to rapid growth in energy demand. The need for a new non-fossil fuel-based energy source is evident from comparing the standard of living, which is dependent on energy, in the most developed countries (e.g., the USA) and developing countries. Although the population of the developing world is five times that of developed nations, they consume less than $40 \%$ of the world's energy supply (World Energy Council, 2001). Therefore, the climate challenge is being significantly complicated with the developing world's continuing transition into a developed world's standard of living, which requires much more energy consumption.

\subsection{Energy demand increase}

Richard Smalley pointed out that in 2004, the global economy consumed the equivalent of 220 million barrels of oil per day, which converted into electricity terms is the equivalent of 14.5 TeraWatts (TW), or 14500000 MegaWatts (MW) (2005). This is an enormous amount of power, which is hard to put in perspective. With a nuclear plant having about $1000 \mathrm{MW}(1 \mathrm{GW})$ of capacity, we would need 14500 nuclear power plants to power the entire world. For reference there were 434 nuclear reactors totalling around 349 GW operating in 32 countries in 1999 (International Atomic Energy Agency, 2000), which produced about $17 \%$ of the world's electricity (ICJT, 2001). To stall climate change, current global GHG emissions must be cut by about $60 \%$ (Hansen and Sato, 2004), and roughly $90 \%$ of all of our energy (not just electricity) comes from fossil fuels. Thus, if the non-GHG-emitting energy were to be supplied solely by nuclear energy, an additional 7481 nuclear power plants would need to be constructed to meet today's energy needs while preventing climate change. The World Energy Council projects that in a high-growth world in which economic growth and energy consumption steadily increases, the global primary energy consumption could reach 24.8 gigatonnes oil equivalent (Gtoe) by 2050 compared to 9.0 Gtoe in 1990 . Converting these values to $\mathrm{kW}$-hrs and dividing by the hours in a year ${ }^{2}$ means that we will need roughly $33 \mathrm{TW}$ of power. To give an idea of the magnitude of this demand, between 1960 and 1986, $1 \mathrm{TW}$-year of electric energy produced in the USA generated approximately 10 trillion dollars of gross national product (World Energy Council, 2004). This enormous increase in energy demand represents a major challenge to the current energy infrastructure. Not only must the magnitude of the energy demands be met, but it must be met in a way that will avoid further $\mathrm{CO}_{2}$ forcing of the climate system. The new means of energy distribution must be cheap, clean, sustainable and from a low $\mathrm{CO}_{2}$-emission source (Pearce, 2002; Smalley, 2005).

Society may choose nuclear energy as its best alternative. If nuclear energy were the primary energy source and all of the world energy growth were supplied by nuclear power (33 TW projected - 14.5 TW current), globally 18500 additional $1 \mathrm{GW}$ nuclear power plants would need to be constructed by 2050. So in total roughly 26000 nuclear power plants having a $1 \mathrm{GW}$ capacity would need to be constructed by 2050 to meet the global demands of non-GHG-emitting energy. If we assume that construction of plants begins in 2010 and is concluded by 2050, 650 new nuclear power plants must be built and put into operation each year or roughly 1.8 per day for the next 40 years. Regardless of how realistic this scenario is, it is useful to quantify the limits of nuclear energy's ability to reduce climate change by mitigating GHG emissions. 


\subsection{GHG emission reduction growth cannibalisation effect}

As was shown in Section 2, the life cycle of a nuclear power plant is not without GHG emissions. In order for a nuclear power plant to have a net negative impact on GHG emissions of the energy supply, first it must produce enough emission-less electricity to offset the emissions that it is responsible for, and then it must continue to produce electricity to offset emissions from existing or potential fossil fuel plants. This can become challenging in view of rapid growth because the construction of additional nuclear power plants to enable the rapid growth rate creates emissions that cannibalise the GHG mitigation potential of all the nuclear power plants viewed as a group. To illustrate this point, it is helpful to view all nuclear power plants as a single aggregate plant or ensemble and look at the aggregate's ability to mitigate emissions as it grows. This ability is first dependent on the energy payback time of the plant. An installed total capacity of the nuclear aggregate plant, $\mathrm{C}_{\mathrm{T}}$ (in $\mathrm{GW}$ ), produces:

$$
E_{T}=t \cdot C_{T}=t \cdot \sum_{n=1}^{N} C_{n}[\mathrm{GW}-\mathrm{hrs}]
$$

of electricity per year, where $t$ is the time the plant is running at capacity in hours in a year, $\mathrm{C}_{\mathrm{n}}$ is the capacity of an individual nuclear power plant and $N$ is the total number of plants. If we assume that in the same year the nuclear industry grows at a rate $r$, it will produce an additional capacity of $\mathrm{rC}_{\mathrm{T}}$. For simplicity, assume that the additional capacity does not produce its electricity, $\mathrm{rC}_{\mathrm{T}} \mathrm{t}$, in that year but only in subsequent years. The time that the nuclear power plant takes to pay for itself in terms of energy it needs over its life cycle, or the energy payback time, is given by the principal energy invested (over the entire life cycle), $P$, divided by energy produced (or fossil fuel energy saved), $S$. Thus if the energy payback time is P/S years, the energy needed for the growth of the entire nuclear power plant ensemble is given by the cannibalistic energy, $\mathrm{E}_{\text {Can }}$ :

$$
\left.E_{\text {Can }}=\frac{P}{S} r C_{T} t \text { [GW-hrs }\right] .
$$

The nuclear power plant ensemble will not produce any net energy if the cannibalistic energy is equivalent to the total energy produced. So by setting Equation (1) equal to Equation (2), the following results:

$$
\frac{P}{S} r C_{T} t=C_{T} t
$$

and simplifies to:

$$
\frac{P}{S}=\frac{1}{r} .
$$

The same analysis is true for GHG emissions. The principle GHG emitted in order to provide for the nuclear power plant divided by the emissions offset every year must be equal to 1 over the growth rate of nuclear power to break even. For example, if the energy payback is five years and the capacity growth is $20 \%$, no net energy is produced and no GHG emissions are offset. 
The energy payback time and the emission payback time are very dependent on the grade of the uranium ore and on the energy mix of the area where the nuclear power plant is located. For example, P/S is between 5.5 years and 92 years based on the US energy mix while 1.5 to 12 years for the European energy mix for an ore grade of $0.1 \%$; and $\mathrm{P} / \mathrm{S}$ is between 4 and 46 years in Europe and 7 years to infinity (no payback) in the USA for an ore grade of $0.01 \%$ (Storm van Leeuwen, 1985). The energy payback time directly limits the growth rate of the nuclear energy ensemble. For example, for a P/S of 10 years for $0.1 \%$ ore (high value payback time of European estimates and low value of US estimates), the limit to the growth rate of the nuclear ensemble is $10 \%$. Inspection of such a high growth rate at first appears promising, until the growth rate is again put back in the perspective of predicted energy demands by mid-century. A simple growth rate formula:

$$
F=I(1+r)^{t}
$$

can be utilised, where $F$ is the final balance of nuclear reactors, $I$ is the initial number or 349 ( $1 \mathrm{GW}$ equivalent) power plants and $t$ is the time in years between 2010 and 2050 or 40 . The necessary growth rate, $r$, to obtain $18849 \mathrm{GW}$ by 2050 is calculated to be $10.5 \%$. This growth rate is very similar to the $10 \%$ limit owing to the energy payback example above. These results are somewhat humbling for any energy policies with the intention of driving down GHG emissions with the deployment of additional nuclear reactors. The goal of GHG mitigation is to actively reduce global emissions - not to simply break even.

The cannibalisation effect, however, is more complicated than the results above would indicate. With each nuclear power plant constructed, the embodied GHG emissions of the next plant will be reduced because the fraction of non-fossil-fuel-based energy has increased. The rate at which this happens also effects the GHG emissions. In addition, it is likely that other sources of energy that have lower $\mathrm{g} \mathrm{CO}_{2}$-eq./kW-hr rates than fossil fuels are also deployed at an expanding rate as economies of scale drive down cost as production increases (e.g., solar photovoltaic) (Pearce, 2005; 2006). This will again drive down the embodied GHG emissions for the nuclear power ensemble. Full vetting of this concept is beyond the scope of this paper and will need to be completed in future studies; however, it is still quite clear from the results discussed here that the claims outlined in the Introduction of 'emission-free nuclear energy' delivering civilisation from global climate destabilisation need to be seriously moderated.

\section{Thermal forcing from waste heat: lessons from the solar unit}

Although thermal forcing owing to increases in the GHG concentration in the atmosphere is the primary cause of current observed global warming, the use of non-GHG-emitting energy sources of terrestrial origin (i.e., any fossil fuel (coal, natural gas, oil) with $\mathrm{CO}_{2}$ sequestration or nuclear power) can also increase the temperature of the Earth. All non-solar sources such as nuclear contribute heat to the Earth, which the Earth must radiate into space by raising its temperature to maintain thermodynamic equilibrium. To illustrate this point, in 1979, Albert Rose suggested a new unit of energy called the 'solar unit' to make the enormous values (such as the multiple TW discussed in Section 4) comprehensible to the non-technically trained reader. The solar unit is defined as the solar power striking Earth as a whole averaged throughout the day and throughout the 
year (Rose, 1979). If it is applied to a part of Earth (e.g., a country), it is equivalent to the solar power falling on that part of Earth. The world use of energy use is in the order of $10^{-4}$ solar units; in the USA, it is $10^{-3}$; and the major metropolitan areas are already consuming power at a rate between 0.1 and 1 solar unit (Rose, 1979).

Following Rose, the thermodynamic equilibrium demands that even if the greenhouse effect is ignored and the generation of power by the world were equal to the solar power incident on the earth, or 1 solar unit, the mean temperature of Earth would rise to about $100^{\circ} \mathrm{C}$ (actually $80^{\circ} \mathrm{C}$ ), obviously unacceptable. Similarly the generation of power of 0.1 solar units would create a temperature rise of $10^{\circ} \mathrm{C}$ and 0.01 solar units would create a rise of $1^{\circ} \mathrm{C}$. Using this semiquantitative reasoning, Rose warned that if industrial society were to increase energy consumption of even these 'clean' sources, an increase in temperature to maintain thermodynamic equilibrium would eventually approach dangerous levels. Rose (1979) suggested this upper limit be a 1K temperature change. More recently, Knox (1999) quantified this effect using a simple model of the earth's radiative balance, which looked at the energy consumption in terms of solar units. He found that the world level in 2000 was $0.688 \times 10^{-4}$ solar units, creating a change in temperature of $0.0077 \mathrm{~K}$, and that if the world were to reach the $1 \mathrm{~K}$ 'upper limit' temperature change, the non-solar energy use would still need to increase by a factor of 130 (Knox, 1999). Thus, this remains a relatively small effect compared to the greenhouse effect, but as energy consumption continues to climb, it is a non-trivial effect that must be considered for a world powered with nuclear energy.

It should be noted that although energy that comes from the sun (such as solar, wind, and hydro) should not cause the 'Rose Effect' because those energy sources are derived from the use of energy that has already set the thermodynamic equilibrium, there are special cases where it would need to be considered. For example, if highly reflective deserts or snow-covered lands are covered in mass with dark absorbent solar photovoltaic panels, the reflectivity of the region would change and less solar flux would escape the atmosphere as light and that additional fraction of energy staying on the planet would cause the same Rose heating effect. This again would be a very small effect, but would need to be taken into account if large centralised solar photovoltaic arrays were used in certain areas. It also points to the better climate stabilisation effects of using distributed solar photovoltaic generation in those areas with less reflectivity. In addition, there has been considerable theoretical work devoted to providing electrical power on the earth from space-based solar collectors, which send concentrated solar energy via microwaves back to Earth (Criswell and Thompson, 1996; Criswell, 1997a-b). This scheme would increase the incoming energy to Earth and create the same Rose heating effect. The space-based solar energy proponents have developed a potential solution to this problem by painting the microwave rectennas white to increase solar reflectivity (Tazawa et al., 1994).

\section{Future work}

As was noted in Sections 2 and 4.2, in order to determine the life-cycle GHG emissions of a nuclear energy plant, the effect of a changing energy mix must be taken into account. A model exists for doing this in economics. In 1949, Leontief developed an economic model of the US economy by dividing it into economic sectors and writing a linear equation for each sector representing how that sector distributes its outputs to the other 
sectors of the economy (Leontief, 1949; 1966). Since then, input-output analysis has grown to become one of the most important methods of economic analysis. 'Cross impacts tables' or 'Leontieff Matrices' need to be developed for all the world energy supplies specifically dedicated to $\mathrm{CO}_{2}$ emissions, where linear equations are determined for each energy source representing how the specific source distributes its energy and emission outputs to the other energy sources. This is not a trivial task, but there has already been some headway made in specific locations. For example, Marpaung et al. (2005), attempt to internalise external costs in electricity development in Indonesia by determining changes in both the emissions of a pollutant caused by the supply-side changes (i.e., in the form of interfuel and technological substitutions in power generation) and the emissions caused by changes in electricity demand owing to the change of electricity price. Tarancón and del Río (2007) provide a more complete input-output methodology combined with a sensitivity analysis to identify and assess the sources of $\mathrm{CO}_{2}$ emissions in an economy, applying it to the case of Spain. As pointed out in Section 2, applying such input-output techniques embodies both the direct and indirect GHG emissions associated with a process or product (Machado et al., 2001). Indirect emissions are those not actually caused directly by the system studied (e.g., nuclear plants control room heating and air-conditioning to maintain thermal comfort for operators), but by the nuclear power plants life-cycle demand, which include the energy and GHG emissions related to all the inputs directly and indirectly involved (Mongelli et al., 2006). In this way, the $\mathrm{CO}_{2}$ emissions induced in the other sectors linked to the nuclear energy sector are taken into account, in the sectors linked to these and so on. In conclusion, the specificity of energy mix must be taken into account using some form of input-output analysis and modified Leontieff Matrices to make complete calculations about $\mathrm{CO}_{2}$ emission impacts of nuclear energy as discussed in this paper.

\section{The ability of nuclear energy to prevent climate change}

Reminiscent of much older claims that nuclear energy was going to be 'too cheap to meter', some claims from very influential energy policy experts that nuclear energy is an 'emission-free' source of energy that will deliver the world from the threat of global climate change, are remarkably overstated. Each stage of the nuclear-fuel cycle including power plant construction, mining/milling uranium ores, fuel conversion, enrichment (or de-enrichment of nuclear weapons), fabrication, operation, decommissioning, and for short- and long-term waste disposal contribute to GHG emissions and the concomitant climate change. The high estimate of total life-time GHG emissions nuclear-fuel cycles provides an improvement in emission rates over the status quo of rampant fossil-fuel combustion, but only by a factor of 12 . To both replace fossil-fuel energy use and meet the future energy demands, nuclear energy production would have to increase by $10.5 \%$ per year from 2010 to 2050 . This large growth rate creates a cannibalistic effect, where new nuclear energy must be used to supply the energy for future nuclear power plants rather than mitigating GHG emissions. This study showed that an energy payback time within the estimated range and the needed growth rate of non-fossil-fuel energy, could limit the ore grade to $0.1 \%$ or higher to simply break even for GHG emissions. This limit on ore grade is significantly higher than the limit imposed by the second law of thermodynamics, where the energy needed to extract and concentrate the uranium is 
equal to the usable energy provided by the fission reaction of the uranium. In addition, any use of nuclear energy directly contributes heat to the Earth, which the Earth must radiate into space by raising its temperature to maintain thermodynamic equilibrium. This currently remains a relatively small effect, but as energy consumption continues to climb, it becomes non-trivial and must be considered for a world powered with nuclear energy. It is clear that the results discussed here demand modesty in claims of 'emission-free nuclear' energy as a means to rescue the planet from global climate destabilisation. These results also indicate that efforts that improve the GHG emissions of the nuclear energy life cycle in the short term should be given a high priority, such as:

- transitioning to enrichment based on gas centrifuge technology

- utilising nuclear plants in combined heat and power systems

- down-blending nuclear weapons stockpiles for nuclear power plant fuel

- utilising only the highest-concentration ores.

Finally, it should be noted that, although this study did not deal directly with economics, all four of these suggestions would likely improve the economic performance of nuclear energy.

\section{Acknowledgement}

The author would like to thank André Maïsseu for his constructive suggestions for the development of this paper.

\section{References}

Argonne National Laboratory (1999) 'Depleted uranium hexafluoride management program: data compilation for the paducah site in support of site-specific NEPA requirements for continued cylinder storage, cylinder preparation, conversion, and long-term storage activities', Argonne National Laboratory, ANL/EAD/TM-109.

Bowers, H.I., Fuller, L.C. and Myers, M.L. (1987) 'Cost estimating relationships for nuclear power plant operation and maintenance', Oak Ridge National Laboratory, ORNL/TM-10563.

Chapman, P.F. (1975) 'Energy analysis of nuclear power stations', Energy Policy, Vol. 3, No. 4, pp.285-298.

Chapman, P.F. and Roberts, F. (1983) Metal Resource and Energy, UK: Butterworth \& Co. Ltd.

Cheney, D., Powell, C.L., O’Neill, P., Norton, G., Veneman, A.M., Evans, D.L., Mineta, N.Y., et al. (2001) 'National energy policy, report of the National Energy Policy Development Group', Washington, DC: US Government Printing Office.

Choppin, G., Liljenzin, J. and Rydberg, J. (2002) Radiochemistry and Nuclear Chemistry, 3rd ed., Chalmers University of Technology.

Criswell, D.R. (1997a) 'Solar-electric power via the moon', Power Technology International, pp.24-26.

Criswell, D.R. (1997b) 'Solar power system based on the moon', in P. Glaser, F.P. Davidson and K. Csigi (Eds.) Solar Power Satellites, Wiley, Chap. 4.11, pp.599-621.

Criswell, D.R. and Thompson, R.G. (1996) 'Data envelopment analysis of space and terrestrial-based large scale commercial power systems for Earth: a prototype analysis of their relative economic advantages', Solar Energy, Vol. 56, No. 1, pp.119-131. 
Deffeyes, K.S. and MacGregor, I.D. (1980) 'World Uranium resources', Scientific American, Vol. 242, No. 1, pp.66-76.

DeLucchi, M. (1991) 'Emissions of greenhouse gases from the use of transportation fuel and electricity', Argonne National Laboratory, ANL/ESD/TM-22, Vol. 2.

DeLucchi, M. (2003) 'A Life Cycle Emission Model (LEM): life cycle emissions from transportation fuels, motor vehicles, transportation modes, electricity use, heating and cooking fuels, and materials', Institute of Transportation Studies, University of California, Davis, CA.

Domenici, P.V. (Chairman) (2004) 'Emissions-free nuclear energy could reduce U.S.'s dangerous over-reliance on natural gas', Senate Committee on Energy and Natural Resources, http://energy.senate.gov/news/rep_release.cfm?id=219287.

Dubin, J.A. and Rothwell, G.S. (1990) 'Subsidy to nuclear power through Price-Anderson liability limit', Contemporary Economic Policy, Vol. 8, No. 3, pp.73-79.

Energy Information Administration (2005) 'Annual Energy Review 2004', Energy Information Administration, DOE/EIA-0384.

Fthenakis, V.M. and Kim, H.C. (2007) 'Greenhouse-gas emissions from solar electric- and nuclear power: a life-cycle study’, Energy Policy, Vol. 35, pp.2549-2557.

Gagnona, L., Belanger, C. and Uchiyama, Y. (2002) 'Life-cycle assessment of electricity generation options: the status of research in year 2001', Energy Policy, Vol. 30, pp.1267-1278.

Hansen, J. and Sato, M. (2004) 'Greenhouse gas growth rates', Proceedings of the Nat. Acad. of Sciences of the USA, Vol. 101, No. 46, pp.16109-16114.

Hoffert, M.I., Caldeira, K., Benford, G., Criswell, D.R., Green, C., Herzog, H., Jain, A.K., et al. (2002) 'Advanced technology paths to global climate stability: energy for a greenhouse planet', Science, Vol. 298, pp.981-987.

Hondo, H. (2005) 'Life cycle GHG emission analysis of power generation systems: Japanese case', Energy, Vol. 30, pp.2042-2056.

ICJT (2001) 'Nuclear Power Plants in the World 2001, The Nuclear Training Centre (ICJT) is part of the Jozef Stefan Institute', http://www.icjt.org/an/tech/jesvet/jesvet.htm (visited 22 May 2007).

Intergovernmental Panel on Climate Change (IPCC) (1995) 'Climate change 1995: the science of climate change, summary for policy makers and technical summary and IPCC Second Assessment Report: Climate Change', United Nations Environment Program and World Meteorological Organization, New York.

Intergovernmental Panel on Climate Change (IPCC) (2001) 'Summary for Policymakers, Climate Change 2001: impacts, adaptation, and vulnerability', United Nations Environment Program and World Meteorological Organization, New York.

Intergovernmental Panel on Climate Change (IPCC) (2007a) 'Climate Change 2007: The physical science basis, summary for policymakers contribution of Working Group I to the Fourth Assessment Report', IPCC Secretariat, Geneva, Switzerland, http://www.ipcc.ch/ SPM2feb07.pdf.

Intergovernmental Panel on Climate Change (IPCC) (2007b) 'Working Group II contribution to the Intergovernmental Panel on Climate Change', Fourth Assessment Report, Climate Change 2007, Climate Change Impacts, Adaptation and Vulnerability.

International Atomic Energy Agency (2000) 'Nuclear power reactors in the world', International Atomic Energy Agency Reference Data Series No. 2, April, Vienna, Austria.

International Atomic Energy Agency (2001) 'Analysis of uranium supply to 2050', International Atomic Energy Agency, Vienna.

Johansson, T., Williams, R., Ishitani, H. and Edmonds, J. (1996) 'Options for reducing $\mathrm{CO}_{2}$ emissions from the energy supply sector', Energy Policy, Vol. 24, pp.985-1003.

Kim, S. and Dale, B.E. (2005) 'Life cycle inventory information of the United States electricity system', International Journal of LCA, Vol. 10, pp.294-310. 
Knox, R.S. (1999) 'Physical aspects of the greenhouse effect and global warming', American Journal of Physics, Vol. 67, No. 12, pp.1227-1238.

Kutscher, C.F. (Ed.) (2007) 'Tackling climate change in the U.S. potential carbon emissions reductions efficiency and carbon emissions reductions from energy efficiency and renewable energy by 2030', American Solar Energy Society, January.

Leeson, G.W. (2002) 'The changing face of the population of Europe: geographical distribution, urbanization, depopulation, and international migration', Stockhom, Sweden: Nordegio.

Leontief, W.W. (1949) The Structure of the American Economy, 1919-1935, New York: Oxford University Press.

Leontief, W.W. (1966) Input-Output Economics, New York: Oxford University Press.

Machado, G., Schaeffer, R. and Worrell, E. (2001) 'Energy and carbon embodied in the international trade of Brazil: an input-output approach', Ecological Economics, Vol. 39, pp.409-424.

Marpaung, C.O.P., Soebagio, A. and Shrestha, R.M. (2005) 'Internalizing external cost in electricity development in Indonesia: a factor decomposition analysis', IEEE/PES Transmission and Distribution Conference \& Exhibition, Asia and Pacific Dalian, China, pp.1-6.

Mongelli, I., Tassielli, G. and Notarnicola, B. (2006) 'Global warming agreements, international trade and energy/carbon embodiments: an input-output approach to the Italian case', Energy Policy, Vol. 34, No. 1, pp.88-100.

Moore, P. (2006) 'Going nuclear: a Green makes the case', Washington Post, 16 April, p.B01.

Myers, N. and Kent, J. (2001) Perverse Subsidies: How Misused Tax Dollars Harm the Environment and the Economy, Washington: Island Press.

Norris, R.S. and Kristensen, H.M. (2005) 'U.S. nuclear forces, 2005', Bulletin of the Atomic Scientists, Vol. 61, No. 1, pp.73-75.

Nuclear Energy Institute (2007) 'Nuclear energy contributes to clean air compliance', http://www.nei.org/index.asp?catnum=2\&catid=41 (accessed 22 May).

Oak Ridge National Laboratory (1995) 'Estimating externalities of nuclear fuel cycles, Report No.8 on the external costs and benefits of fuel cycles: a study by the US Department of Energy and the Commission of the European Communities', Oak Ridge National Laboratory, ORNL/M-2500.

Pearce, J. and Lau, A. (2002) 'Net energy analysis for sustainable energy production from silicon-based solar cells', in R. Cambell-Howe (Ed.) Proceedings of American Society of Mechanical Engineers Solar 2002: Sunrise on the Reliable Energy Economy.

Pearce, J. and Russill, C. (2005) 'Interdisciplinary environmental education: communicating and applying energy efficiency for sustainability', Applied Environmental Education and Communication, Vol. 4, No. 1, pp.65-72.

Pearce, J.M. (2002) 'Photovoltaics - a path to sustainable futures', Futures, Vol. 34, No. 7, pp.663-674.

Pearce, J.M. (2005) 'Using the internet to reduce market risk for alternative energy sources: the case of large-scale solar photovoltaic production', First Monday, Vol. 10, No. 8, http://www.firstmonday.org/issues/issue10_8/pearce/index.html.

Pearce, J.M. (2006) 'Catalyzing mass production of solar photovoltaic cells using university driven green purchasing', International Journal of Sustainability in Higher Education, Vol. 7, No. 4, pp.425-436.

Pearce, J.M. and Hanlon, J.T. (2007) 'Energy conservation from systematic tire pressure regulation, energy policy', Vol. 35, No. 4, pp.2673-2677.

Pearce, J.M. and Miller, L.L. (2006) 'Energy service companies as a component of a comprehensive university sustainability strategy', Int. J. of Sustainability in Higher Education, Vol. 7, No. 1, pp.16-33. 
Pearce, J.M., Johnson, S.J. and Grant, G.B. (2007) '3D-mapping optimization of embodied energy of transportation', Resources, Conservation and Recycling, Vol. 51, pp.435-453.

Rohatgi, U., Jo, J.H., Lee, J.C. and Bari, R.A. (2002) 'Impact of the nuclear option on the environment and the economy', Nuclear Technology, Vol. 137, pp.252-264.

Rose, A. (1979) 'A global view of solar energy in rational units', Phys. Stat. Sol (a), Vol. 56, pp.11-25.

Rotty, R.M., Perry, A.M. and Reister, D.B. (1975) 'Net energy from nuclear power', Institute for Energy Analysis, Oak Ridge Associated Universities, TN, IEA-75-3.

Sailor, W.C., Bodansky, D., Braun, C., Fetter, S. and van der Zwaan, B. (2000) 'NUCLEAR POWER: a nuclear solution to climate change?', Science, Vol. 288, No. 5469, pp.1177-1178.

Smalley, R. (2005) 'Future global energy prosperity: the Terawatt challenge', Materials Research Society Bulletin, Vol. 30, pp.412-417.

Storm van Leeuwen, J.W. (1985) 'Nuclear uncertainties: energy loans for fission power', Energy Policy, Vol. 13, pp.253-266.

Tarancón, M.A. and del Río, P. (2007) ' $\mathrm{CO}_{2}$ emissions and intersectoral linkages. The case of Spain', Energy Policy, Vol. 35, pp.1100-1116.

Tazawa, M., Jin, P., Miki, T., Yoshimura, K., Igarashi, K. and Tanemura, S. (1994) 'Optical properties and radiative cooling power of white paints', National Industrial Research Institute of Nagoya. Meisei Industrial Co., Ltd., Hosoe-cho, Inasa-gun, Shiquoka, 431-1204, Japan.

Thomas, S. (2005) 'The economics of nuclear power: analysis of recent studies', Public Services International Research Unit (PSIRU), http://www.psiru.org/reports/2005-09-E-Nuclear.pdf (accessed 22 May).

United States Enrichment Corporation (2001) Megatons to Megawatts, http://www.usec.com/v2001 _02/HTML/megatons.asp (accessed 22 May 2007).

US Department of Energy (1983) Energy Technology Characterizations Handbook: Environmental Pollution and Control Factors, 3rd ed., Department of Energy, Washington, DC, DOE/EP-0093.

US Department of Energy (2002a) 'Yucca Mountain Science and Engineering Report technical information supporting site recommendation consideration', Revision 1, Office of Civilian Radioactive Waste Management, Department of Energy, DOE/RW-0539-1.

US Department of Energy (2002b) 'Final environmental impact statement for a geologic repository for the disposal of spent nuclear fuel and high-level radioactive waste at Yucca Mountain', Office of Civilian Radioactive Waste Management, Department of Energy, DOE/EIS-0250, Nye County, Nevada.

US Department of Energy (2007) 'Department of Energy Issues \$14 Million in funding opportunity announcements to U.S. universities for nuclear research', http://www.ne.doe.gov/ (accessed 19 May).

Vattenfall, A.B. (2004) 'Generation Nordic countries certified environmental product declaration of electricity from Ringhals NPP', S-P-00026, http://www.environdec.com/reg/026/Chapters/ Dokument/EPD-Ringhals.pdf.

Voorspools, K.R. and D'haeseleer, W.D. (2000) 'An evaluation method for calculating the emission responsibility of specific electric applications', Energy Policy, Vol. 28, pp.967-980.

Voorspools, K.R., Peersman, I. and D'haeseleer, W.D. (2005) 'A comparative analysis of energy and $\mathrm{CO}_{2}$ taxes on the primary energy mix for electricity generation', Int. J. Energy Res., Vol. 29, pp.879-890.

World Energy Council (2001) 'Lunar solar power system: industrial research, development, and demonstration', 18th Congress, Buenos Aires, University of Houston, USA, October.

World Energy Council (2004) 'Energy data centre: global energy scenarios to 2050 and beyond', http://www.worldenergy.org/wec-geis/edc/scenario.asp (accessed 22 May). 


\section{Notes}

1 These include cost-effectiveness in the context of government subsidies including liability protection, among others, dealt with elsewhere (Dubin and Rothwell, 1990; Myers and Kent, 2001; Thomas, 2005), world uranium supply, political site locations (i.e., NIMBY protestors), accident/melt-down probability, radioactive waste, storage, decommissioning, national security, and terrorists/rogue state nuclear threats, sabotage, etc.

21 Tonne of Oil Equivalent (toe) $=11630$ kiloWatt Hour $(\mathrm{kW}-\mathrm{hr}), 1 \mathrm{TW}=10^{12}$ Watts. 